\title{
On the Development of High Power DC-DC Step-Down Converter with Energy Recovery Snubber
}

\author{
Alok Singh, Mangesh B. Borage, Sunil R. Tiwari, and A. C. Thakurta \\ Power Supplies and Industrial Accelerator Division, Raja Ramanna Centre for Advanced Technology, \\ Indore 452013, India \\ Correspondence should be addressed to Alok Singh, aloksingh@rrcat.gov.in
}

Received 27 December 2011; Revised 28 March 2012; Accepted 29 March 2012

Academic Editor: Jose Pomilio

Copyright ( 2012 Alok Singh et al. This is an open access article distributed under the Creative Commons Attribution License, which permits unrestricted use, distribution, and reproduction in any medium, provided the original work is properly cited.

The effect of switching losses on the efficiency of a switch mode power converter and methods adopted for its improvement using an energy recovery lossless snubber has been presented. A comparative analysis of various types of soft switching techniques along with effects of dissipative and nondissipative snubbers on efficiency of the converter has been carried out before zeroing in on the selected scheme. The selected snubber serves the dual function of a turn-on and turn-off snubber and thereby reducing the switching losses both during turn-on and turn-off transients, resulting in improved efficiency of the converter. A detailed design procedure of the snubber for high-power applications taking into account various effects such as diode reverse recovery, diode voltage stress, and minimum and maximum duty cycle limits, has been presented in this paper. Importance of practical aspects in layout to minimize wiring inductance is also highlighted. A high-power prototype of buck converter has been developed to experimentally validate the theoretical design and analytical observations.

\section{Introduction}

Switch mode power supplies are popular because of higher efficiency, smaller size, and lighter weight $[1,2]$. Low weight and smaller size comes about because operation is significantly at a higher frequency range, and thus the magnetic components are quite smaller in size and weight [3]. High switching frequencies in turn results in large switching losses and stresses in power device because during the turn-on and turn-off transients the power device has to withstand high voltage and current simultaneously $[4,5]$. Large $d i / d t$ and $d v / d t$ transitions also induces significant amount of electromagnetic interference (EMI) in the circuit which in turn pollute the utility systems [6]. This problem, if left unattended, may result in lower efficiency and larger size of converters owing to increased size of the heat sinks and EMI filters. Efforts are made in order to alleviate the aforementioned limitations and to enable operation at still higher frequencies while maintaining better conversion efficiency [7].

Snubbers are an essential part of power electronic systems. They are small network of passive components which forms a part of power switching circuits to reduce switching losses and stresses in power devices [8]. But, as the switching losses in the main switch are dissipated in form of heat in snubber resistors, the overall efficiency of the converter is deteriorated. Various soft switching techniques have been proposed in the literature $[1,9,10]$ to obtain soft switching of power devices while at the same time maintaining higher overall efficiency. But this is achieved at the cost of increased design complexity of power and control circuits and thereby increasing circuit cost and deteriorating the system reliability [5].

Energy recovery snubber poses a solution to the problem as it is simpler, reliable, and cheaper than most of the soft switching techniques and also helps in reducing the switching losses without deteriorating the overall system efficiency. The energy stored in an energy recovery snubber is either moved back to the input or ahead to the output in a nondissipative manner $[5,6,8,11,12]$. Energy recovery snubbers can be further classified as turn-on, turn-off, and combined function snubbers. Turn-on snubbers are basically nondissipative current snubbers which control the rate of 


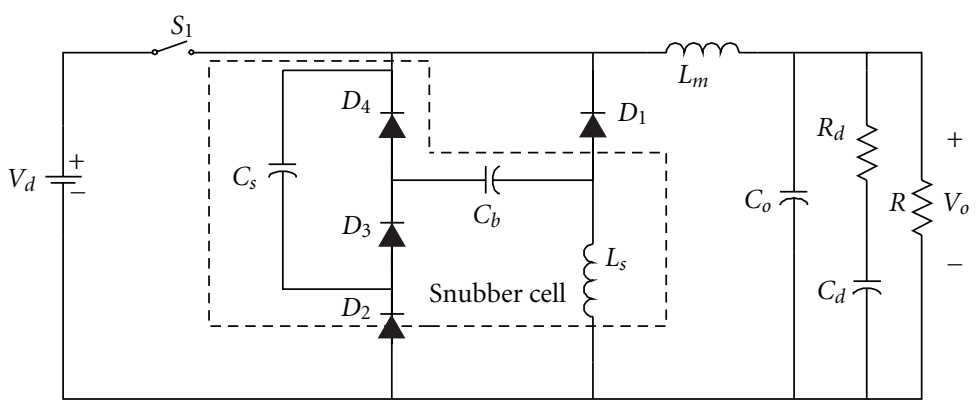

FIGURE 1: Buck converter with energy recovery snubber.

rise of current in the main switch at turn-on transient and thereby achieving zero current switching (ZCS) at turn-on transient of the switch $[8,13]$, while turn-off snubbers are nondissipative voltage snubbers which control growth rate of voltage across the switch during turn-off transient and thus help in achieving zero voltage switching (ZVS) at turnoff transient $[8,14-17]$. The combined function snubber, also called as turn-on and turn-off snubber, serves the dual function of achieving ZCS turn-on and ZVS turn-off of the switch during turn-on and turn-off transients, respectively, and hence includes the functionality of both turn-on and turn-off snubber in a single circuit [5]. An energy recovery turn-on and turn-off snubber is thus selected for further investigation and implementation in a high power $\mathrm{dc}-\mathrm{dc}$ converter.

Although, synthesis and optimization of various snubbers have been widely reported in the literature for low power dc-dc converters $[1,5,6,9-19]$, the issues related to design, optimization, application, and practical aspects pertaining to their use in high power $\mathrm{dc}$-dc converters are not reported. This paper presents the design and optimization of energy recovery snubber with wide operating range for high power $\mathrm{dc}-\mathrm{dc}$ converters. The presented work is based on the analytical results reported in [5]. Brief operation of the energy recovery snubber is presented in Section 2 followed by design parameters of dc-dc converter in Section 3, design and optimization of energy recovery snubber in Section 4, simulation and experimental results in Section 5, and conclusions in Section 6.

\section{Operation of Energy Recovery Snubber}

Snubber shown in Figure 1 is an energy recovery turn-on plus turn-off snubber also called as $3 \mathrm{D}-2 \mathrm{C}-1 \mathrm{~L}$ snubber. The snubber network has been called so because it has three diodes, two capacitors, and one inductor. Growth rate of reverse recovery current is controlled by snubber inductor $L_{s}$, while growth rate of voltage across switch is controlled by snubber capacitor $C_{s}$. Energy recovery is achieved by discharging the buffer capacitor $C_{b}$ to the output. The key waveforms of the buck converter with energy recovery snubber are shown in Figure 2 [5]. During turn-on process, the diode recovery current is the major cause of the switching losses and EMI. The rate of rise of current and peak reverse recovery current is restricted by the snubber inductor $L_{s}$ to
Table 1: Prototype specifications.

\begin{tabular}{lc}
\hline Maximum output power & $25 \mathrm{~kW}$ \\
Switching frequency & $25 \mathrm{kHz}$ \\
Filter inductor, $L_{m}$ & $800 \mu \mathrm{H}$ \\
Filter capacitor, $C_{o}$ & $3 \mu \mathrm{F}$ \\
Filter damping capacitor, $C_{d}$ & $15 \mu \mathrm{F}$ \\
Filter damping resistor, $R_{d}$ & $15 \Omega$ \\
\hline
\end{tabular}

suppress the switching loss. During turn-off process, the rate of rise of drain-source voltage is restricted by the snubber capacitor $C_{s}$ to obtain ZVS turn off and to reduce EMI noises.

The freewheeling diode is also commutated with ZVS during both turn-on and turn-off. The energy absorbed in snubber inductor $L_{s}$ and snubber capacitor $C_{s}$ is transferred to $C_{b}$ instead of being dissipated, which is subsequently transferred to the output. Detailed operation of this snubber with various modes of operation is given in [5].

\section{Design Parameters of DC-DC Converter}

A high-power prototype of buck converter with maximum output voltage and current ratings of $450 \mathrm{~V}$ and $55.5 \mathrm{~A}$, respectively, has been developed to experimentally validate the theoretical design of energy recovery snubber. The design parameters of the buck converter are given in Table 1.

The insulated gate bipolar transistor (IGBT) module used in the prototype is SKM100GAR123D [20].

\section{Design and Optimization of Energy Recovery Snubber}

Design and optimization of energy recovery snubber are described in six steps as given below. Subsequently, a design flow diagram for snubber parameters calculation is also presented in Figure 3.

Step 1 (Choice of $C_{s}$ ). The snubber capacitor $C_{s}$ shown in Figure 1 is mainly responsible for ZVS turn-off of switch $S_{1}$. Thus, the discharging time of $C_{s}$ should be quite larger than the fall time $t_{f}$ of the switch to ensure proper ZVS turnoff of the switch. When the switch $S_{1}$ turns off, the output current $I_{o}$ flows through $D_{2}$ to discharge $C_{s}$ to the output. 


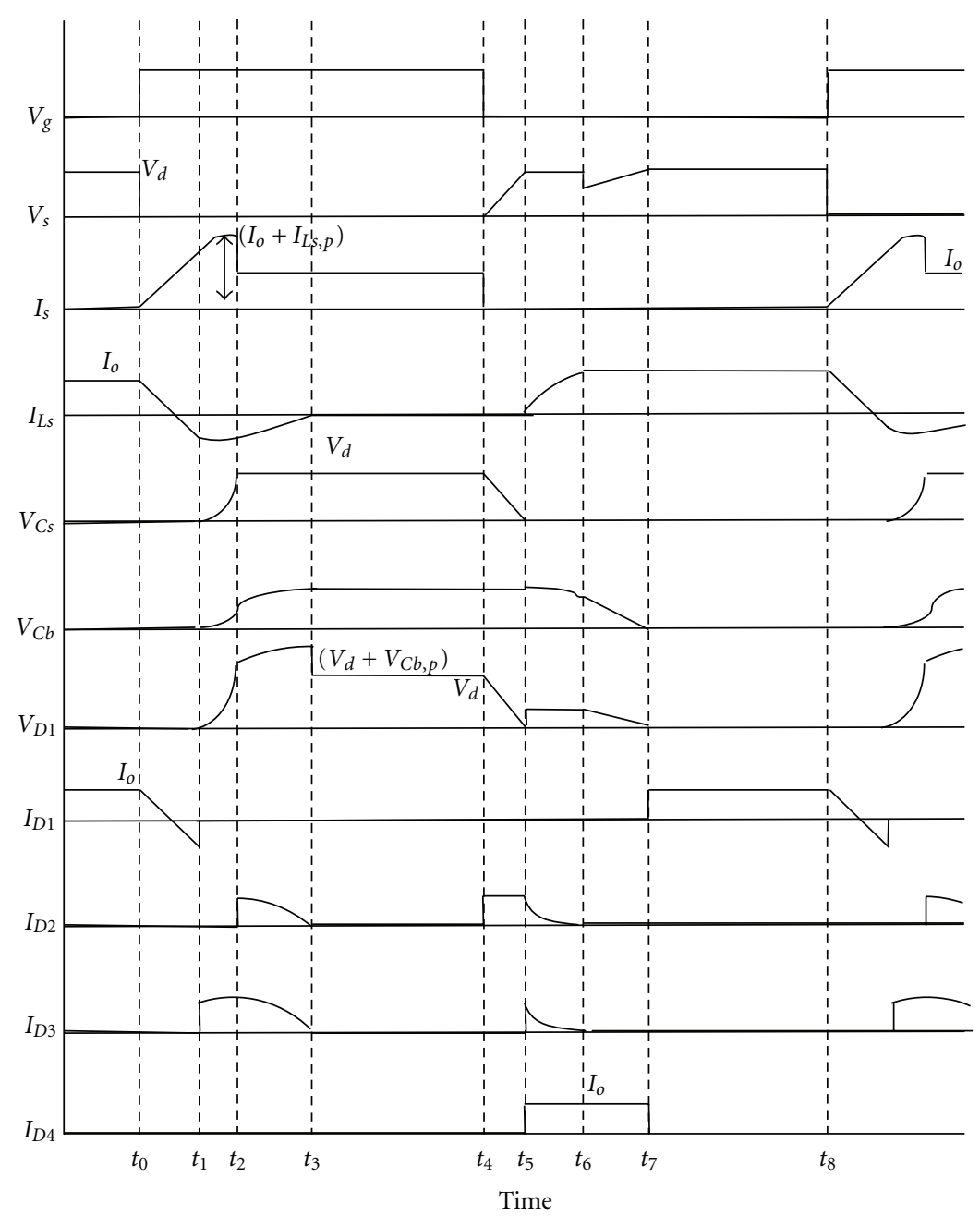

FIGURE 2: Key waveforms of the buck converter with energy recovery snubber.

During this period, capacitor discharges linearly. If the time taken by $C_{s}$ to discharge completely from the value of $V_{d}$ to zero is $t_{d}$, then, capacitance $C_{s}$ can be written in terms of output current $I_{o}$, input dc voltage $V_{d}$ and discharge time $t_{d}$ as follows:

$$
C_{s}=\frac{I_{o} t_{d}}{V_{d}}
$$

As typically the fall time $t_{f}$ of the switch is around 100 ns. Thus, to ensure proper ZVS turn-off of the switch, discharge time $t_{d}$ is taken to be approximately five-times the fall time of switch $t_{f}$, that is, $500 \mathrm{~ns}$. Therefore, for $\left(I_{o}\right)_{\max }$ $=55.55 \mathrm{~A},\left(V_{d}\right)_{\min }=504 \mathrm{~V}$, and $t_{d}=500 \mathrm{~ns}$, the value of snubber capacitance $C_{s}$ comes out to be $0.055 \mu \mathrm{F}$ from (1). The nearest available value of snubber capacitance used in the practical circuit is $0.047 \mu \mathrm{F}$.

Step 2 (Choice of $L_{s}$ ). When the switch $S_{1}$ shown in Figure 1 is turned on, the growth rate of the drain current is restricted by the snubber inductor to softly turn on the switch. During this duration, rate of fall of main diode current $i_{D 1}$, which is also equal to the rate of rise of switch current, is given as follows:

$$
\frac{d i_{D 1}}{d t}=\frac{V_{d}}{L_{s}}
$$

Values of $d i_{D 1} / d t$ calculated for various values of $L_{s}$ and $V_{d}=600 \mathrm{~V}$ using (2) have been listed in column 2 in Table 2. Column 3 in Table 2 shows the estimated values of reverse recovery current $I_{\text {rr }}$ flowing through main diode $D_{1}$ for the corresponding values of $d i_{D 1} / d t$ listed in column 2 . These values have been estimated from $I_{\mathrm{rr}} \mathrm{v} / \mathrm{s} d i_{D f} / d t$ curve given in the datasheet of IGBT module [20].

Step 3 (Choice of $C_{b}$ ). Buffer capacitance $C_{b}$ is expressed in terms of $L_{s}, C_{s}, V_{d}, I_{\mathrm{rr}}$, and $V_{C b, p}$ as follows [5]:

$$
C_{b}=\frac{L_{s} I_{\mathrm{rr}}^{2}+C_{s} V_{d}^{2}}{V_{C b, p}^{2}} .
$$

As the voltage stress of freewheeling diode $D_{1}$ is equal to $V_{d}$ plus $V_{C b, p}$, thus the peak voltage appearing across buffer capacitor $C_{b}$ is capped at $235 \mathrm{~V}$ to keep the voltage rating 


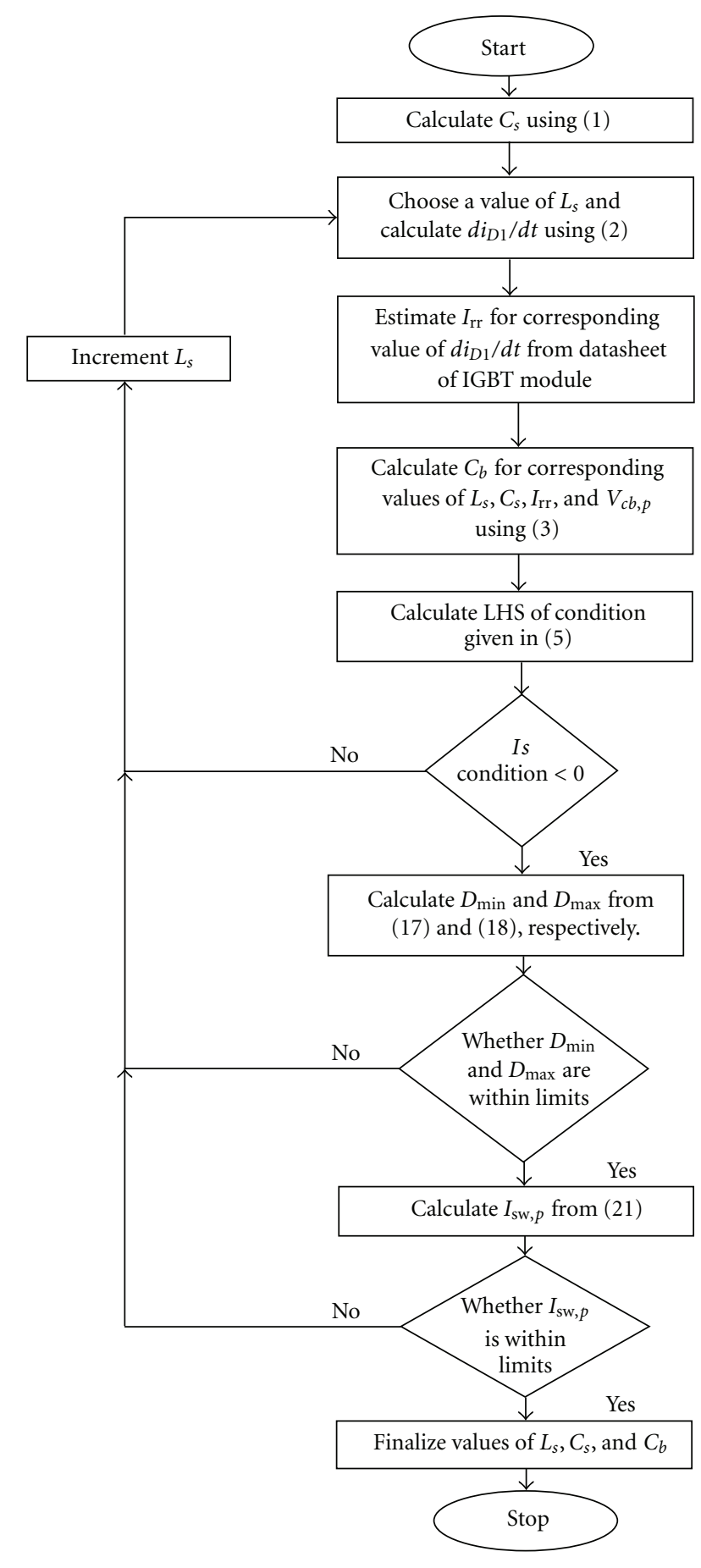

FIGURE 3: Design flow diagram for snubber parameters calculation.

of $D_{1}$ within limits (maximum voltage rating of diode $D_{1}$ is $1200 \mathrm{~V}$ ). Hence, the peak voltage appearing across diode $D_{1}$ is given by.

$$
V_{D_{1}, p}=V_{d}+V_{C b, p} \cong 850 \mathrm{~V} .
$$

Thus, values of $C_{b}$ calculated for corresponding values of $L_{s}, C_{s}, V_{d}, I_{\mathrm{rr}}$, and $V_{C b, p}$ are listed in column 4 in Table 2.
Step 4 (Checking for Condition). The necessary condition which ensures the proper ZCS turn-on and ZVS turn-off operation of circuit is given in [5] and can also be written as follows:

$$
\frac{1}{2} L_{s} I_{o}^{2}-\frac{1}{2} L_{s} I_{\mathrm{rr}}^{2}-\frac{1}{2} C_{s} V_{d}^{2}<0
$$

Column 5 in Table 2 calculates the left hand side (LHS) of inequality given in (5) and the result is TRUE if LHS is negative, while FALSE otherwise.

Step 5 (Check for $D_{\min }$ and $D_{\max }$ ). Maximum and minimum duty cycle limits are imposed on the buck converter due to finite time taken by the snubber circuit for its operation. During this duration, the normal operation of buck converter is suspended. Maximum duty cycle limit occurs due to the snubber circuit operation at switch turn-off transition, while minimum duty cycle limit occurs due to the snubber circuit operation at switch turn-on transition. Thus, the duty cycle limits can be obtained by calculating the time taken by the snubber both during turn-on and turn-off transitions.

Various stages of operations have been discussed in [5]. Out of 8 stages of operation of buck converter circuit described in [5], snubber is active during 6 stages $\left(t_{0}<t<\right.$ $\left.t_{1}\right),\left(t_{1}<t<t_{2}\right),\left(t_{2}<t<t_{3}\right),\left(t_{4}<t<t_{5}\right),\left(t_{5}<t<\right.$ $\left.t_{6}\right)$, and $\left(t_{6}<t<t_{7}\right)$. Time duration of all these 6 stages are calculated here for values of $L_{s}$ varying from $1 \mu \mathrm{H}$ to $10 \mu \mathrm{H}, C_{s}=0.047 \mu \mathrm{F}, V_{d}=600 \mathrm{~V}$, peak voltage across buffer capacitor $V_{C b, p}=235 \mathrm{~V}$, and output current $I_{o}=56 \mathrm{~A}$. To do this, expressions for time durations for these stages are derived based on equations describing voltages and currents given in [5]. They are summarized as follows.

Time duration $T_{d 1}$ of stage 1 is given by

$$
T_{d 1}=\left(t_{1}-t_{0}\right)=\frac{L_{s}}{V_{d}}\left(I_{o}+I_{\mathrm{rr}}\right) .
$$

Time duration $T_{d 2}$ of stage 2 is given by

$$
\begin{aligned}
T_{d 2} & =\left(t_{2}-t_{1}\right) \\
& =\frac{1}{\omega_{1}}\left\{\sin ^{-1}\left(\frac{C_{s} V_{d}}{C_{b} \sqrt{\left(I_{\mathrm{rr}} Z_{1}\right)^{2}+V_{d}^{2}}}\right)+\tan ^{-1} \frac{V_{d}}{I_{\mathrm{rr}} Z_{1}}\right\},
\end{aligned}
$$

where $Z_{1}$ and $\omega_{1}$ are given in (8),

$$
\begin{gathered}
Z_{1}=\sqrt{\frac{L_{s}\left(C_{s}+C_{b}\right)}{C_{s} C_{b}}}, \\
\omega_{1}=\sqrt{\frac{C_{s}+C_{b}}{L_{s} C_{s} C_{b}}} .
\end{gathered}
$$

Time duration $T_{d 3}$ of stage 3 is given by

$$
T_{d 3}=\left(t_{3}-t_{2}\right)=\frac{1}{\omega_{2}} \tan ^{-1}\left(\frac{C_{b} I_{s 2} Z_{2}}{C_{s} V_{d}}\right),
$$


TABLE 2: Calculation of snubber parameters.

\begin{tabular}{lcccccccc}
\hline$L s(\mu \mathrm{H})$ & $d i / d t(\mathrm{~A} / \mathrm{us})$ & $I_{\mathrm{rr}}(\mathrm{A})$ & $C_{\mathrm{b}}(\mu \mathrm{F})$ & \multicolumn{2}{c}{ Condition } & $I_{\text {sw,pk }}(\mathrm{A})$ & Min. duty cycle limit & Max. duty cycle limit \\
\hline 1 & 600 & 35 & 0.328565 & -7504.5 & TRUE & 182.6 & 0.028185861 & 0.969112264 \\
2 & 300 & 22 & 0.323911 & -5808 & TRUE & 144.7242 & 0.040937446 & 0.962884825 \\
3 & 200 & 20 & 0.328112 & -4356 & TRUE & 129.0297 & 0.051743372 & 0.955668148 \\
$\mathbf{4}$ & $\mathbf{1 5 0}$ & $\mathbf{1 8}$ & $\mathbf{0 . 3 2 9 8 5 1}$ & $-\mathbf{2 8 3 6}$ & TRUE & $\mathbf{1 1 9 . 4 5 4 3}$ & $\mathbf{0 . 0 6 1 1 5 1 5 1}$ & $\mathbf{0 . 9 4 5 9 3 6 3 3 7}$ \\
5 & 120 & 16 & 0.329561 & -1260 & TRUE & 112.7242 & 0.069572661 & - \\
6 & 100 & 15 & 0.330828 & 273 & FALSE & 107.9057 & 0.077569317 & - \\
7 & 85.714286 & 15 & 0.334903 & 1728.5 & FALSE & 104.4218 & 0.085468737 & - \\
8 & 75 & 15 & 0.338977 & 3184 & FALSE & 101.634 & 0.093078882 & - \\
9 & 66.666667 & 15 & 0.343051 & 4639.5 & FALSE & 99.34127 & 0.100457752 & - \\
10 & 60 & 15 & 0.347125 & 6095 & FALSE & 97.41529 & 0.107647168 & -
\end{tabular}

where $I_{s 2}, Z_{2}$ and $\omega_{2}$ are given by (10), and (11), respectively:

$$
\begin{gathered}
I_{s 2}=\frac{V_{d}}{Z_{1}} \sin \left(\omega_{1} T_{d 2}\right)+I_{\mathrm{rr}} \cos \left(\omega_{1} T_{d 2}\right), \\
Z_{2}=\sqrt{\frac{L_{s}}{C_{b}}}, \\
\omega_{2}=\sqrt{\frac{1}{L_{s} C_{b}}} .
\end{gathered}
$$

Time duration $T_{d 4}$ of stage 5 is given by

$$
T_{d 4}=\left(t_{5}-t_{4}\right)=\frac{C_{s} V_{d}}{I_{o}} .
$$

Time duration $T_{d 5}$ of stage 6 is given by

$$
T_{d 5}=\left(t_{6}-t_{5}\right)=\frac{1}{\omega_{2}} \sin ^{-1}\left(\frac{I_{o} Z_{2}}{V_{C b, p}}\right) .
$$

Time duration $T_{d 6}$ of stage 7 is given by

$$
T_{d 6}=\left(t_{7}-t_{6}\right)=\frac{C_{s} V_{d}}{I_{o}} \cos \left(\omega_{2} T_{d 5}\right),
$$

where $T_{d 5}$ is given by (13).

The switch $S_{1}$ must be on from $t=t_{0}$ at least till $t=t_{3}$ when $I_{L s}$ becomes zero. This governs the minimum duty cycle limit which is given by

$$
\text { Minimumduty cycle limit }\left(D_{\min }\right)=\frac{T_{d 1}+T_{d 2}+T_{d 3}}{T_{s}},
$$

where $T_{d 1}, T_{d 2}$, and $T_{d 3}$ are given by (6), (7), and (9) respectively, and $T_{s}$ is the switching time period. Values of minimum duty cycle limit calculated for $T_{s}=40 \mu \mathrm{s}$, corresponding to the switching frequency of $25 \mathrm{kHz}$ are listed in column 7 in Table 2.

The switch $S_{1}$ must be maintained in off condition from $t=t_{4}$ to at least $t=t_{7}$ when the buffer capacitor $C_{b}$ is discharged completely. This dictates maximum duty cycle limit given by

$$
\text { Maximumduty cycle limit }\left(D_{\max }\right)=1-\left(\frac{T_{d 4}+T_{d 5}+T_{d 6}}{T_{s}}\right) \text {. }
$$

Step 6 (Calculation for Ratings). Peak value of the drain current of switch $S_{1}$ appears when $V_{C b}+V_{C s}$ becomes equal to $V_{d}$ and is obtained by the summation of output current $I_{o}$ and peak snubber inductor current $I_{L s, p}$ which is given by [5]:

$$
I_{L s, p}=\frac{\sqrt{V_{d}^{2}+\left(I_{\mathrm{rr}} Z_{1}\right)^{2}}}{Z_{1}},
$$

where,

$$
Z_{1}=\sqrt{\frac{L_{s}\left(C_{s}+C_{b}\right)}{C_{s} C_{b}}} .
$$

Thus, peak switch current is given by

$$
I_{\mathrm{sW}, p}=I_{o}+I_{L s, p}
$$

Therefore, from (17), (18), and (19), peak value of switch current $I_{\mathrm{sw}, p}$ is calculated for corresponding values of $L_{s}, C_{s}$, $C_{b}, V_{d}, I_{\mathrm{rr}}$, and $I_{o}$ and listed in column 6 in Table 2.

For the buck converter prototype, specifications of which are given in Table 1, iterative calculations have been done for buffer capacitance of snubber $C_{b}$, peak current rating of switch $I_{\mathrm{sw}, \mathrm{pk}}$, and minimum and maximum duty cycle limits for various values of snubber inductance $L_{s}$ ranging from $1 \mu \mathrm{H}$ to $10 \mu \mathrm{H}$ while taking $C_{s}=0.047 \mu \mathrm{F}, V_{d}=600 \mathrm{~V}$, peak voltage across buffer capacitor $V_{C b, p}=235 \mathrm{~V}$, and output current $I_{o}=56 \mathrm{~A}$ as shown in Table 2 . Highlighted values in the table show the selected snubber parameters. $I_{\text {rr }}$ shown in table is the estimated reverse recovery current of the main diode $D_{1}$.

Values of maximum duty cycle limit calculated for $T_{s}=$ $40 \mu$ s are listed in column 8 in Table 2 . It is important to note that the choice of snubber components, therefore, also governs the operating range of the converter in addition to various voltage and current stresses described previously.

Snubber parameters, therefore, should be selected after making a tradeoff between the maximum permissible switch current rating, diode voltage rating, and operating duty cycle range provided that the circuit satisfies the inequality given in (5) which ensures proper soft switching operation of snubber over that range. 


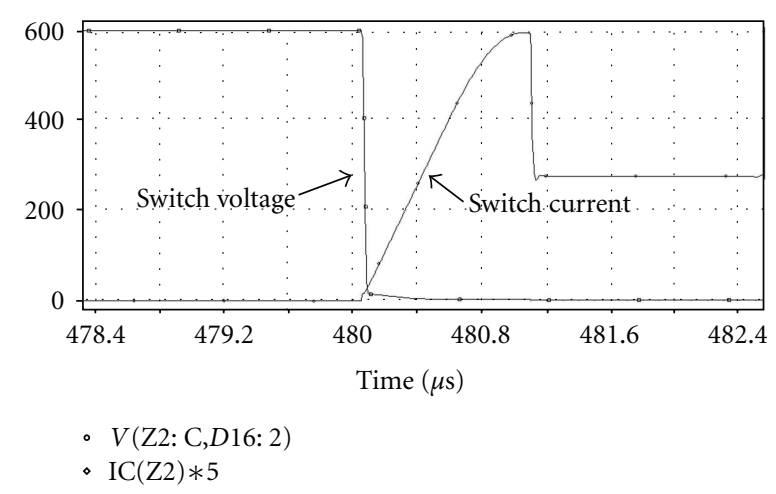

FIgURE 4: ZCS turn-on of switch $S_{1}$.

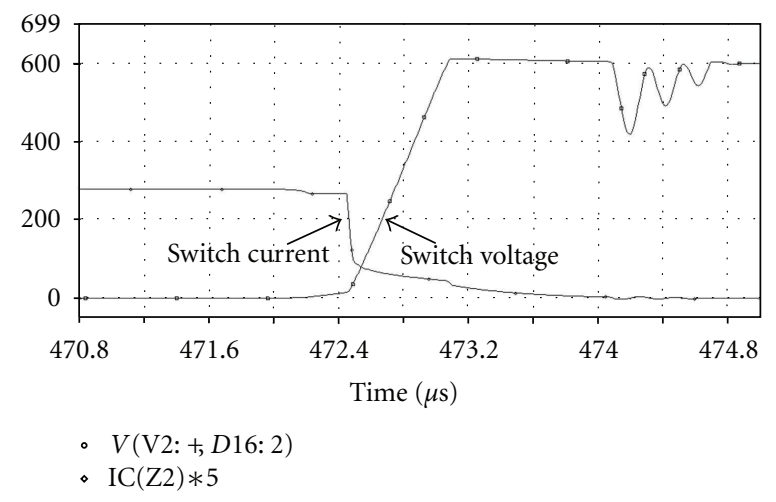

Figure 5: ZVS turn-off of switch $S_{1}$.

Based on the calculations illustrated in Table 2, the following component values are chosen:

$$
\begin{aligned}
& L_{s}=4 \mu \mathrm{H}, \\
& C_{s}=0.047 \mu \mathrm{F}, \\
& C_{b}=0.33 \mu \mathrm{F}, \\
& I_{s \mathrm{w}, p}=119.45 \mathrm{~A}, \\
& V_{D 1, p}=850 \mathrm{~V}, \\
& V_{C s, p}=616 \mathrm{~V}, I_{C s, p}=55.5 \mathrm{~A}, \text { and } \\
& V_{C b, p}=235 \mathrm{~V}, I_{C b, p}=55.5 \mathrm{~A} .
\end{aligned}
$$

Diodes APT60D100B are used for snubber diodes [21]. Inductor $L_{s}$ is developed in EE65.32.18 core with 4 turns and an air gap of $1.4 \mathrm{~mm}$.

\section{Simulation and Experimental Results}

Simulation results for voltage and current waveforms across switch in the presence of energy recovery snubber are shown in Figures 4 and 5, respectively, during on-time and off-time transitions for input dc voltage, $V_{d}=616 \mathrm{~V}$ and output current, $I_{o}=56 \mathrm{~A}$. From Figures 4 and 5, respectively, it is observed that energy recovery snubber helps in achieving ZCS turn-on and ZVS turn-off of switch $S_{1}$ at turn-on and turn-off transients.

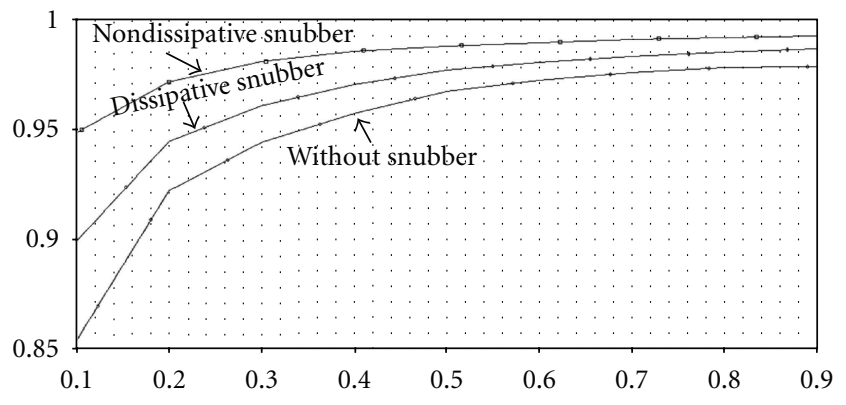

FIGURE 6: Efficiency comparison of buck converter with dissipative and nondissipative snubbers.

Simulation results for comparison of efficiency of buck converter with and without dissipative and nondissipative snubbers are shown in Figure 6 in which $x$-axis represents duty cycle variation from 0.1 to 0.9 , while $y$-axis represents efficiency of buck converter. Dissipative snubber used in simulation consists of two cells one of which is responsible for achieving ZCS turn-on of the switch, while the other one ensures its ZVS turn-off. The turn-on snubber cell is placed in series with the switch and consists of an inductor $(4 \mu \mathrm{H})$ connected in parallel with the series combination of a resistor $(5 \Omega)$ and an ideal diode. While the turn-off snubber cell is placed across the switch and consists of a capacitor $(0.047 \mu \mathrm{F})$ placed in series with a parallel combination of a resistor $(68 \Omega)$ and an ideal diode. Nondissipative snubber components used in simulation are same as summarized in Section 4. From Figure 6 it is observed that efficiency of the buck converter reduces when a dissipative snubber is used to limit the switching losses. This is because of the fact that in dissipative snubbers switching losses in power devices are transferred to the dissipative component in the snubber thereby reducing overall efficiency of the converter. But, in contrast to this, nondissipative snubber reduces the switching losses by temporarily storing the energy of one switching transient in a buffer and then transferring it either back to the input or ahead to the output during the next switching transient in a nondissipative manner and thereby, reducing the switching losses while at the same time increasing the efficiency of the converter. The improvement in efficiency with energy recovery snubber is evident in simulation waveforms of Figure 6.

The simulation waveforms shown in Figures 4 and 5 are valid only for ideal circuits which are free of any wiring inductances. But, in practical circuits, these wiring inductances play a significant role in introducing undesirable effects on the circuit operation. This can be demonstrated by introducing some wiring inductance in series with the input dc supply of simulation circuit. Figure 7 shows the simulation waveforms with the effects of wiring inductance of $100 \mathrm{nH}$ introduced in the simulation circuit.

From Figure 7, it is observed that the wiring inductances have significant undesirable effect on the circuit performance. During turn-off transition, ringing is observed in switch voltage and current waveforms which results in an overlap between the two during the transition interval and thereby resulting in switching loss at turn-off transition 


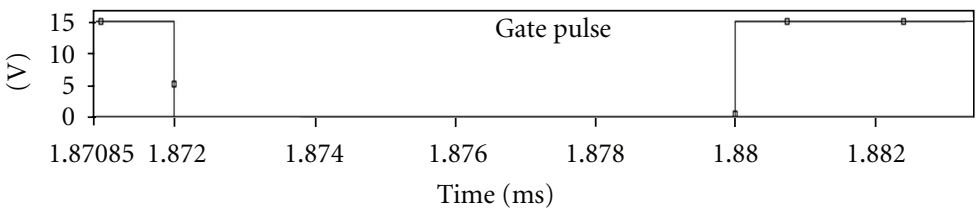

- $V(\mathrm{~V} 4:+, \mathrm{V} 4:-)$

(a)

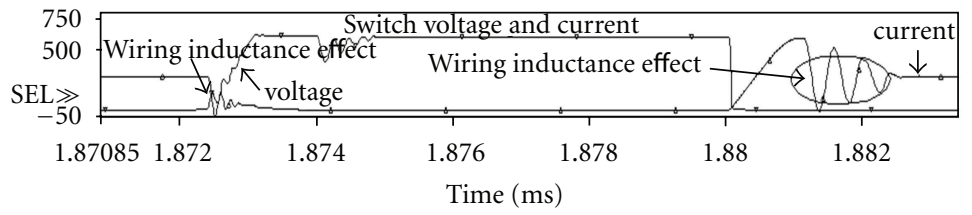

$\nabla V(\mathrm{Z} 2: \mathrm{C}, \mathrm{Z} 2: \mathrm{E})$

$\triangle \mathrm{IC}(\mathrm{Z} 2) * 5$

(b)

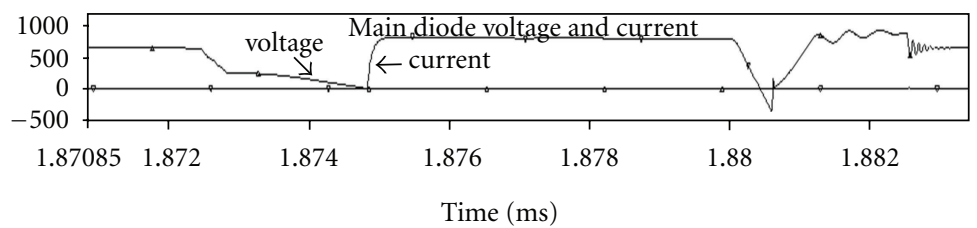

$\nabla I(D 19) * 14$

$\triangle V(D 19: 2, D 19: 1)$

(c)

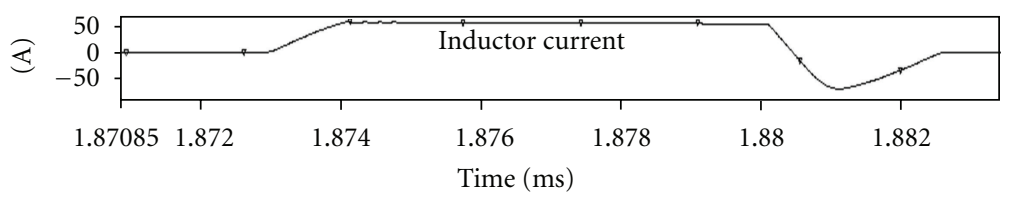

$\nabla I(\mathrm{~L} 3)$

(d)

Figure 7: Simulation waveforms with effect of wiring inductance for $D=0.5, V_{d}=616 \mathrm{~V}$, and $I_{o}=56 \mathrm{~A}$ : gate pulses, voltage and current in $S_{1}$, voltage and current in $D_{1}$, and current in $L_{s}$.

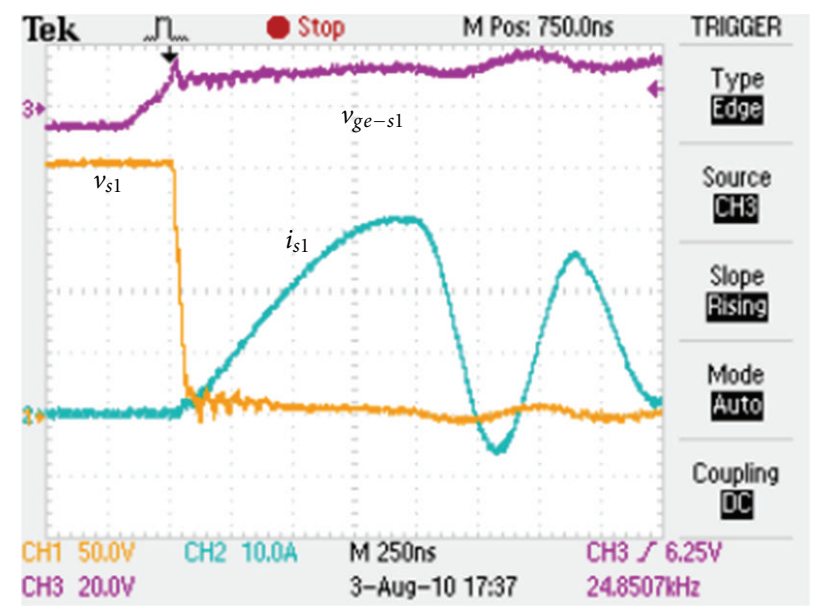

(a)

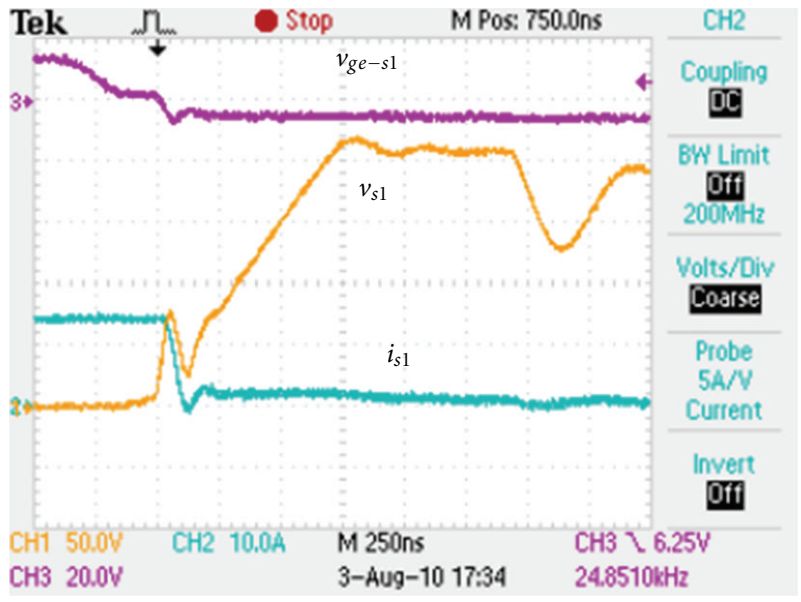

(b)

FIGURE 8: Experimental waveforms of $v_{s 1}(50 \mathrm{~V} / \mathrm{div})$ and $i_{s 1}(10 \mathrm{~A} / \mathrm{div})$ at (a) turn-on transition and (b) turn-off transition. In both parts, $\mathrm{Ch} 3$ shows gate pulse for switches $\left(v_{g e-s 1}, 20 \mathrm{~V} / \mathrm{div}\right)$ and XScale is $250 \mathrm{~ns} / \mathrm{div}$. 


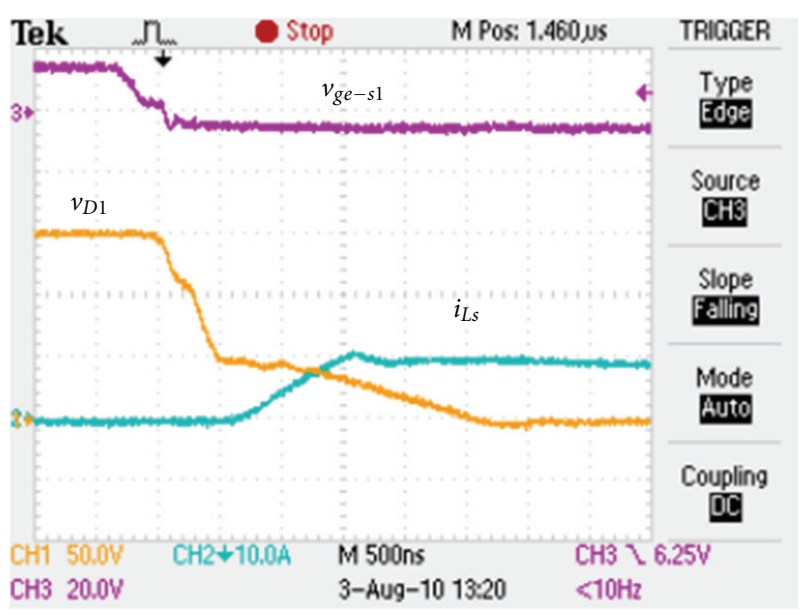

(a)

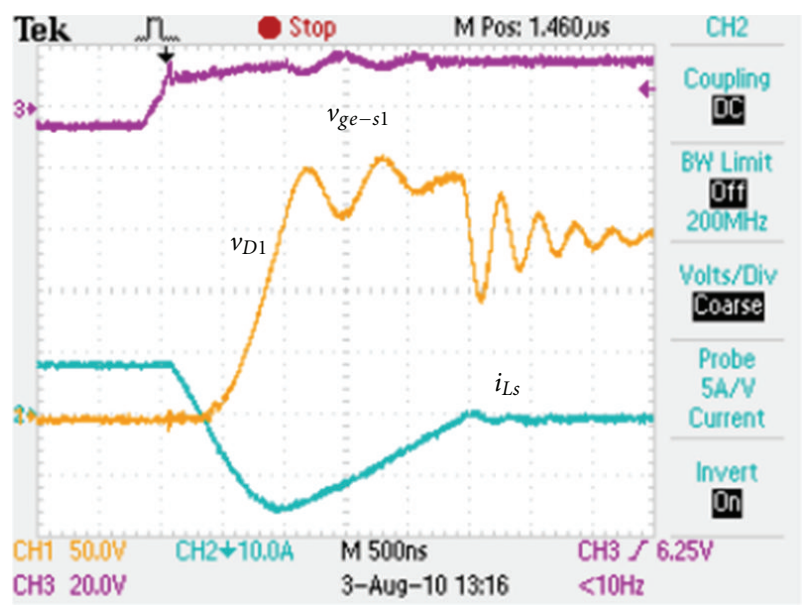

(b)

FIgURE 9: Experimental waveforms of $v_{D 1}(50 \mathrm{~V} /$ div $)$ and $i_{L s}$ $(10 \mathrm{~A} / \mathrm{div})$ at (a) diode turn-on transition and (b) diode turn-off transition. In both parts, Ch3 shows gate pulse for switches $\left(v_{g e-s 1}\right.$, $20 \mathrm{~V} / \mathrm{div}$ ) and XScale is $500 \mathrm{~ns} / \mathrm{div}$.

as shown in Figure 7. Ringing is also observed in switch current after turn-on transition which disrupts the normal functioning of the buck converter during this interval as shown in Figure 7. Thus, significant steps should be taken during the development phase of the converter to minimize these wiring inductances by making a judicious arrangement for the assembly of snubber and other components of the converter. This can be done by prudently placing the components containing high frequency currents as close to each other as possible and thereby minimizing the wiring length which in turn results in reduced wiring inductance. Another way to reduce wiring inductance is to use twisted cables or to use flat wide conductors and using copper strips.

Figures 8(a) and 8(b) shows the experimental waveforms of the voltage across the switch $\left(v_{s 1}\right)$ and current through it $\left(i_{s 1}\right)$ at turn on and turn off transitions, respectively, for $D=0.5$ and $V_{d}=200 \mathrm{~V}$. From Figure 8, it is clear that the switch turns on under ZCS condition and turns off under ZVS condition which is in agreement with the theoretical

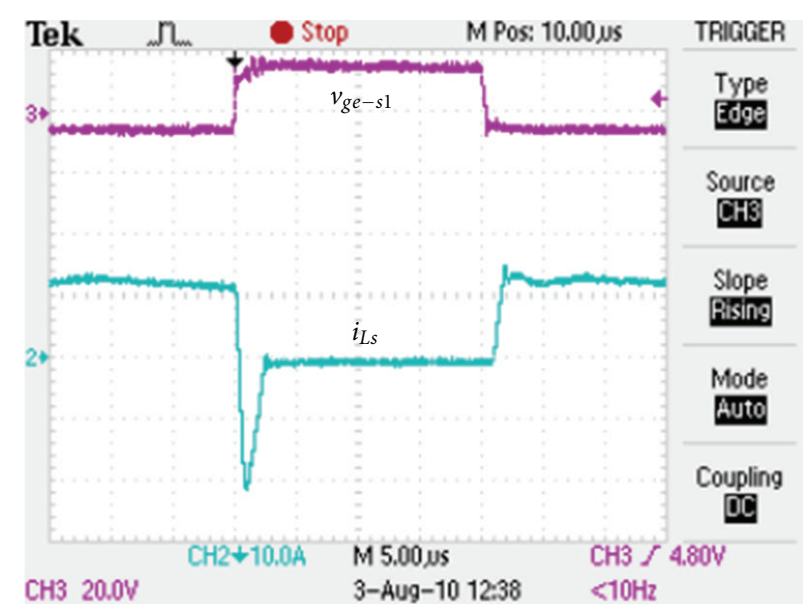

(a)

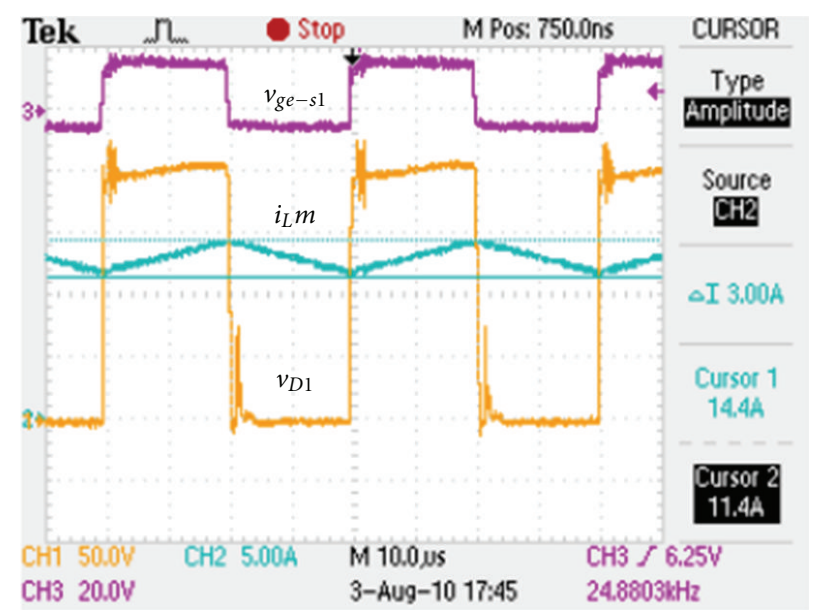

(b)

FIGURE 10: Experimental waveforms of (a) $i_{L s}$ (10 A/div) with XScale of $5 \mu \mathrm{s} /$ div and (b) $v_{D 1}(50 \mathrm{~V} /$ div $), i_{L m}(5 \mathrm{~A} /$ div $)$ with XScale of $10 \mu \mathrm{s} /$ div. In both parts, Ch3 shows gate pulse for switches $\left(v_{g e-s 1}\right.$, $20 \mathrm{~V} /$ div).

analysis of switch voltage and current waveforms and also with the simulation results presented in Figure 7.

Figures 9(a) and 9(b) shows the experimental waveforms of main diode $D_{1}$ voltage $\left(v_{D 1}\right)$ and snubber inductor $L_{s}$ current $\left(i_{L s}\right)$ at turn on and turn off transitions respectively for $D=0.5$ and $V_{d}=200 \mathrm{~V}$.

Since snubber inductor $L_{s}$ is connected in series with the main diode $D_{1}$, as shown in Figure 1, a part of snubber inductor current flows through main diode $D_{1}$ both during turn-on and turn-off transitions. As, it is difficult to monitor current waveform in main diode, snubber inductor current is observed here to demonstrate the ZVS turn-on and ZVS turn-off of the main diode $D_{1}$. From Figure 9, it is clear that the main diode $D_{1}$ also turns-on and turns-off under ZVS condition which is in agreement with the theoretical analysis of main diode voltage and current waveforms and also with the simulation results presented in Figure 7.

Figure 10(a) shows the snubber inductor $L_{s}$ current waveform for full cycle of operation while Figure 10(b) shows 


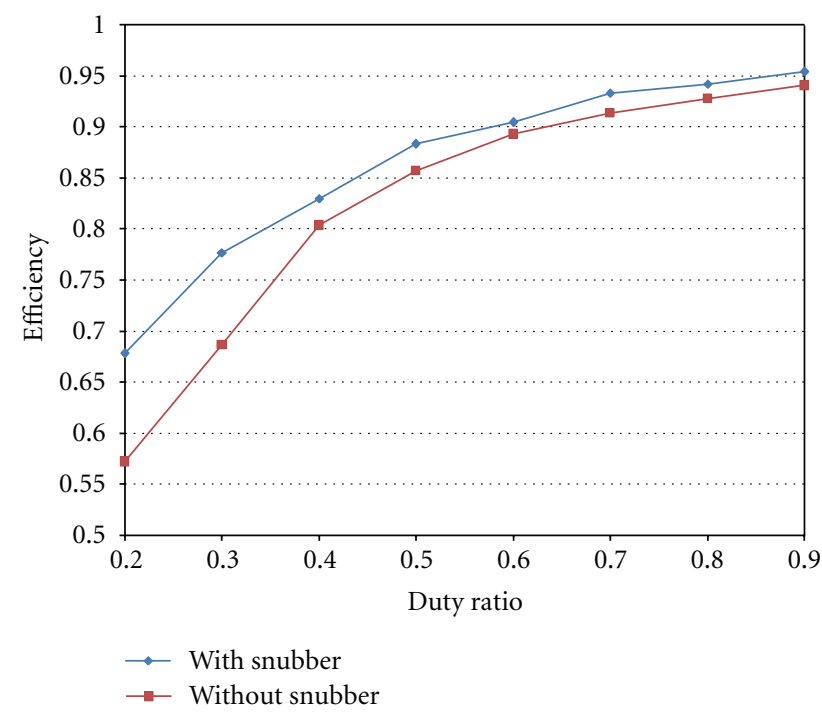

FIGURE 11: Measured efficiency of buck converter with and without nondissipative snubber at $V_{d}=100 \mathrm{~V}$.

the voltage and current waveforms of main diode $D_{1}$ and output filter inductor $L_{m}$, as shown in Figure 1, respectively for $D=0.5$ and $V_{d}=200 \mathrm{~V}$. Figure 10(a) demonstrates that the snubber inductor current waveform is in accordance with the theoretical analysis and also with the simulation results presented in Figure 7. While Figure 10(b) shows that the voltage and current waveforms respectively of $D_{1}$ and $L_{m}$ are in agreement with the theoretical analysis of basic buck converter circuit.

Figure 11 shows the graph for efficiency comparison of buck converter with and without nondissipative snubber. Graph is plotted for input dc voltage of $100 \mathrm{~V}$ because full load operation of circuit could be detrimental for the devices in absence of snubber. It is quite clear from this graph that the efficiency of buck converter improves by using nondissipative snubber in the circuit, which is also in agreement with the simulation result as shown in Figure 6.

\section{Conclusions}

Snubbers are essential part of switching power electronic circuits as these helps in reducing switching losses, stresses on semiconductor devices as well as EMI. Various types of soft switching snubbers are available in literature out of which an energy recovery snubber is selected for high power dcdc step-down converter owing to its distinct advantages over other types. For high power applications, optimization of snubber parameters is done by making a tradeoff between the maximum permissible switch current rating, diode voltage rating and operating duty cycle range provided that the circuit satisfies an inequality which ensures proper soft switching operation of snubber over that duty cycle range. As wiring inductance brings about undesirable effects in the circuit operation, efforts should be made to minimize the wiring inductance by judicious selection of circuit layout. Experimental waveforms shows that the energy recovery snubber helps in reducing switching losses as well EMI by achieving ZCS turn-on and ZVS turn-off of switch $S_{1}$ and also ZVS turn-on and turn-off of diode $D_{1}$ without deteriorating overall efficiency of the converter. Practical effects of the wiring inductance on circuit performance are also demonstrated by experimental waveforms.

\section{References}

[1] Y. Zhang and P. C. Sen, "A new soft-switching technique for buck, boost, and buck-boost converters," IEEE Transactions on Industry Applications, vol. 39, no. 6, pp. 1775-1782, 2003.

[2] L. C. de Freitas, P. Roberto, and C. Gomes, "High-power highfrequency ZCS-ZVS-PWM buck converter using a feedback resonant circuit," IEEE Transactions on Power Electronics, vol. 10, no. 1, pp. 19-24, 1995.

[3] T. F. Wu and S. A. Liang, "A systematic approach to developing single-stage soft switching PWM converters," IEEE Transactions on Power Electronics, vol. 16, no. 5, pp. 581-593, 2001.

[4] K. H. Liu and F. C. Y. Lee, "Zero-voltage switching technique in DC/DC converters," IEEE Transactions on Power Electronics, vol. 5, no. 3, pp. 293-304, 1990.

[5] C. J. Tseng and C. L. Chen, "Passive lossless snubbers for dc/dc converters," in Proceedings of the 13th Annual Applied Power Electronics Conference and Exposition (APEC '98), pp. 10491054, February 1998.

[6] K. M. Smith and K. M. Smedley, "Properties and synthesis of passive lossless soft-switching PWM converters," IEEE Transactions on Power Electronics, vol. 14, no. 5, pp. 890-899, 1999.

[7] M. R. Amini and H. Farzanehfard, "Novel family of PWM softsingle-switched DC-DC converters with coupled inductors," IEEE Transactions on Industrial Electronics, vol. 56, no. 6, pp. 2108-2114, 2009.

[8] P. C. Todd, Snubber Circuits: Theory, Design and Application, Unitrode Corporation, 1993.

[9] A. Elasser and D. A. Torrey, "Soft switching active snubbers for DC/DC converters," IEEE Transactions on Power Electronics, vol. 11, no. 5, pp. 710-722, 1996.

[10] R. L. Lin, Y. Zhao, and F. C. Lee, "Improved soft-switching ZVT converters with active snubber," in Proceedings of the 13th Annual Applied Power Electronics Conference and Exposition (APEC'98), pp. 1063-1069, February 1998.

[11] C. J. Tseng and C. L. Chen, "A passive lossless snubber cell for nonisolated PWM DC/DC converters," IEEE Transactions on Industrial Electronics, vol. 45, no. 4, pp. 593-601, 1998.

[12] K. Seshu Babu, M. Borage, R. Saxena, S. Tiwari, and S. Kotaiah, "Evaluation of passive lossless snubbers for high frequency switching converters," in Proceedings of the IEEE 13th Annual Symposium on Power Systems, Bangalore, India, November 2004.

[13] S. J. Finney, D. J. Tooth, J. E. Fletcher, and B. W. Williams, "The application of saturable turn-on snubbers to IGBT bridge-leg circuits," IEEE Transactions on Power Electronics, vol. 14, no. 6, pp. 1101-1110, 1999.

[14] C. A. Munoz B, "Study of a new passive lossless turnoff snubber," in Proceedings of the IEEE International Power Electronics Conference (PESC'98), pp. 147-152, 1998.

[15] T. Tanaka, T. Ninomiya, and K. Harda, "Design of a non dissipative turn-off snubber in a forward converter," in Proceedings of the 19th Annual IEEE Power Electronics Specialists Conference Record (PESC'88), pp. 789-796, 1988. 
[16] R. Petkew, "Analysis and optimisation of a non-dissipative turn-off snubber for IGBT," in Proceedings of the 19th International Telecommunications Energy Conference (INTELEC '97), pp. 50-57, 1997.

[17] T. Ninomiya, T. Tanaka, and K. Harada, "Analysis and optimization of a non-dissipative LC turn-off snubber," IEEE Transactions on Power Electronics, vol. 3, no. 2, pp. 147-156, 1988.

[18] K. M. Smith Jr. and K. M. Smedley, "Lossless, passive soft switching methods for inverters and amplifiers," in Proceedings of the 28th Annual IEEE Power Electronics Specialists Conference (PESC'97), pp. 1431-1439, June 1997.

[19] X. He, B. W. Williams, S.J. Finney et al., "Analysis and comparison of a new passive lossless snubber for high frequency converter application," in Proceedings of the 5th European Conference on Power Electronics and Applications, no. 2, pp. 344-349, 1993.

[20] Datasheet of IGBT module SKM100GAR123D, http://www .semikron.com/products/data/cur/assets/SKM100GAL123D_ 22890020.pdf.

[21] Datasheet of snubber diodes APT60D100B, http://www2.microsemi.com/datasheets/60D100B(G)_S(G).PDF. 

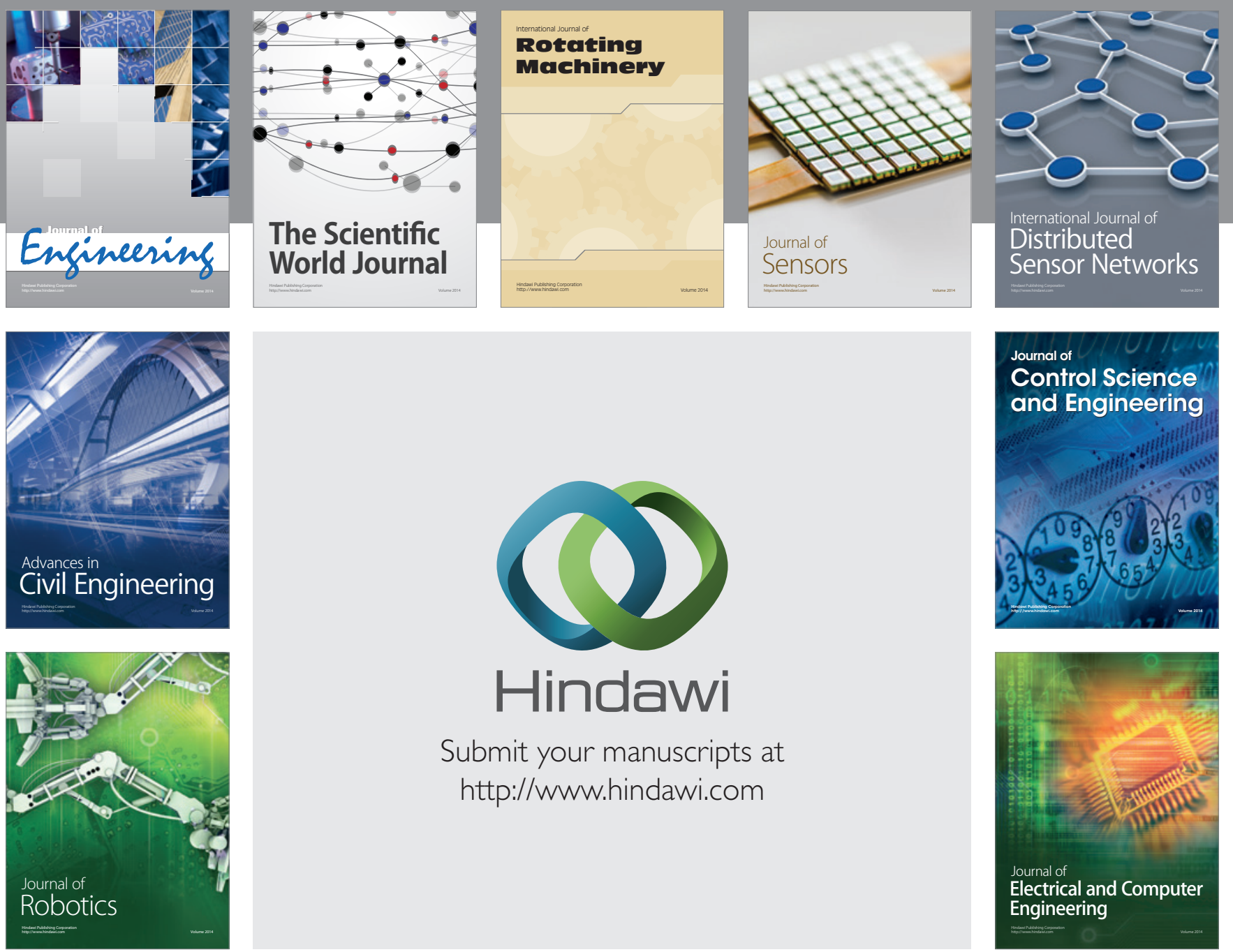

Submit your manuscripts at

http://www.hindawi.com
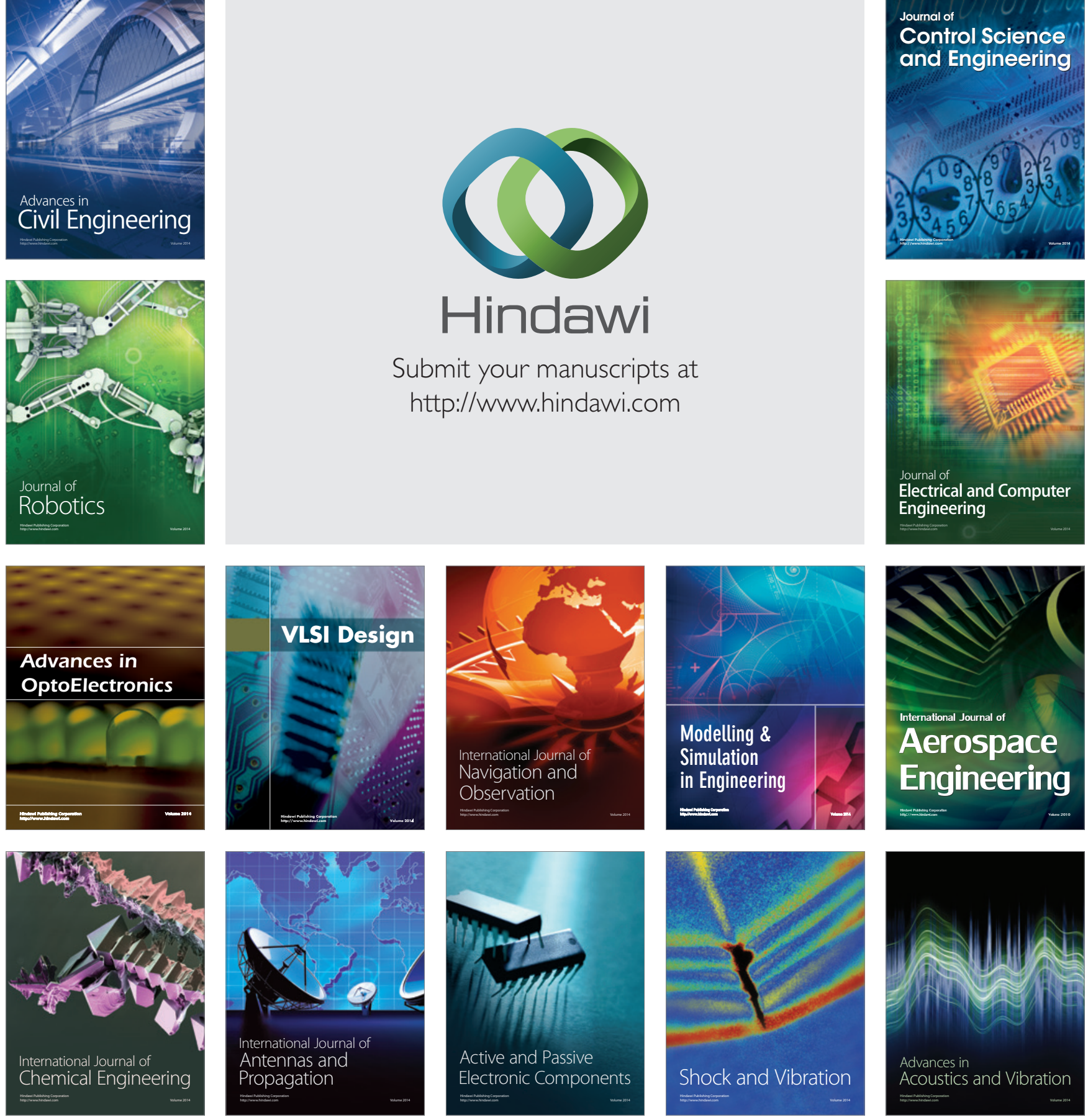